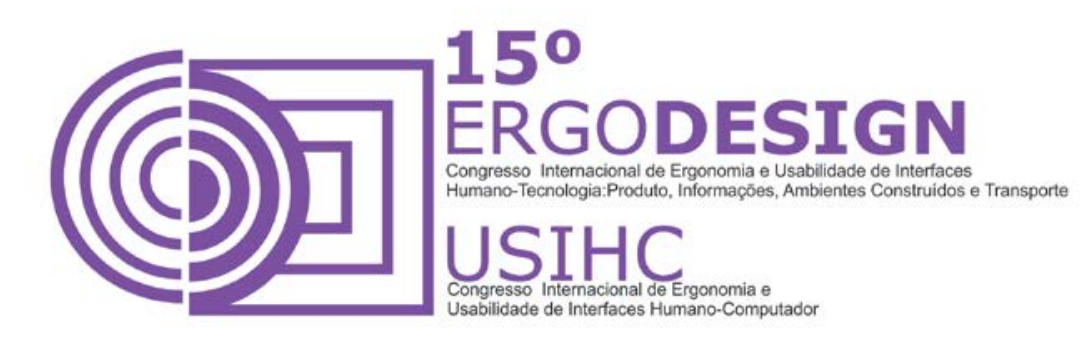

\title{
ADEQUAÇÃO ESTRUTURAL DE UM QUARTO HOSPITALAR
}

\section{SUITABILITY OF A HOSPITAL ROOM}

\author{
BARELA, Jefferson (1); \\ FERREIRA, Ana Cristina Maurício (2); \\ BONFIM, Gabriel Henrique Cruz (3); \\ PASCHOARELLI, Luis Carlos (4)
}

(1) CEETEPS - Centro Estadual de Educacao Tecnologica Paula Souza, Especialista

e-mail:jefferson.barela@gmail.com

(2) PPGDesign-UNESP, Mestre

e-mail:ana emdurb@yahoo.com.br

(3) PPGDesign-UNESP, Mestre

e-mail:gh cb@hotmail.com

(4) PPGDesign-UNESP, Doutor

e-mail:paschoarelli@faac.unesp.br

\begin{abstract}
RESUMO
Dentre os problemas de interface tecnológica observados em ambientes hospitalares, destacam-se os riscos de quedas. Esses ambientes deveriam considerar a garantia de melhores condições de saúde, segurança e bem estar de pacientes e profissionais. Apesar do avanço tecnológico, ainda existem inúmeros problemas de usabilidade. Em um ambiente hospitalar, os pacientes fazem uso de cadeira de rodas, macas, escadinha de apoio ou uso de drogas e analgesias e isso os deixam propensos a sofrer quedas. Portanto, o presente estudo demonstra parâmetros projetuais para adequação de um quarto hospitalar baseado em estudos preliminares e análise de quartos hospitalares já existentes.
\end{abstract}

Palavras-chave: Risco de queda, Ergonomia, Ambiente hospitalar.

\section{ABSTRACT}

Among the technological interface problems observed in hospitals, it is highlighted the risk of falling. Those environments are increasingly seeking to ensure better health, safety and welfare of patients and professionals. Despite technological advances, there are still many usability problems. In a hospital, patients use wheelchairs, stretchers, support ladder or they take drugs and analgesia and that leaves 


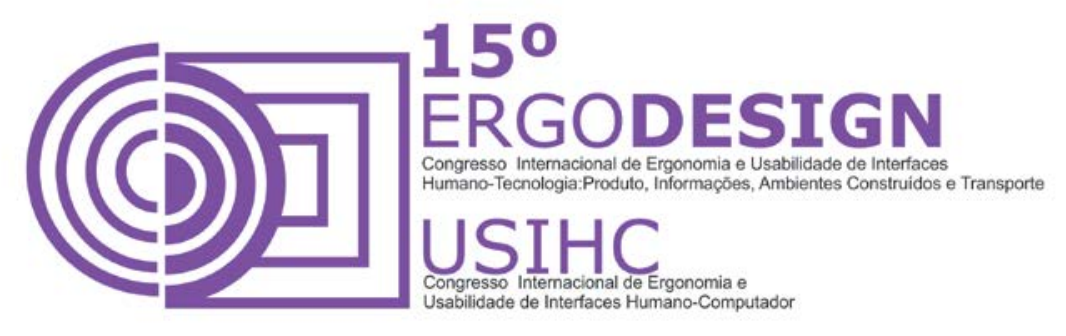

them prone to suffer falls. Therefore, this study aimed to the suitability of a hospital room based on preliminary research and analysis of existing hospital rooms.

Keywords: Risk of falling, Ergonomics, Hospital environment.

\section{INTRODUÇÃO}

Ambientes hospitalares são cada vez mais projetados e desenvolvidos com o intuito de garantir melhores condições de saúde, segurança e bem estar de pacientes e profissionais. Novos métodos e tecnologias têm sido aplicados e, apesar desta evolução, ainda surgem inúmeros problemas de carência de usabilidade com seus usuários.

Sendo assim, com a contribuição do design ergonômico, onde se procura soluções para o projeto de interfaces (ambientes, equipamentos, mobiliários, sistemas informacionais, dispositivos de segurança, entre outros), nas quais os usuários não são apenas os trabalhadores da área da saúde, mas também os pacientes e seus respectivos acompanhantes; é possível o desenvolvimento de projetos que garantam a satisfação, conforto e bem estar dos usuários. Entre os muitos problemas de interface tecnológica observados nos ambientes hospitalares, destacam-se os riscos relacionados às quedas.

Esse problema de quedas em ambientes hospitalares ainda é muito comum devido a vários fatores como, por exemplo, idade avançada, uso de medicamentos que interferem no sistema neuromuscular ou até mesmo no uso excessivo de mobiliários nos quartos, levando em consideração que toda pessoa que está de dentro de um ambiente hospitalar e faz uso de cadeira de rodas, macas, escadinha de apoio ou uso de drogas e analgesias está propensa a sofrer quedas (BARELA, et. al. 2012).

Dessa forma, o presente estudo teve por objetivo demonstrar o projeto de adequação de um quarto hospitalar com base em análise de outros quartos hospitalares que apresentaram irregularidades e também em um estudo preliminar onde foram apontadas as maiores dificuldades de locomoção dos pacientes bem como os maiores riscos de queda.

\section{FUNDAMENTAÇÃO TEÓRICA}

\subsection{Risco de Quedas}

A queda é um evento acidental que tem como resultado a mudança de posição do indivíduo para um nível mais baixo, em relação a sua posição inicial, com incapacidade de correção em tempo hábil e apoio no solo (RIBEIRO et al., 2006).

A queda pode ocorrer com indivíduos de todas as faixas etárias, entretanto, o fator queda na população idosa tem sido um grande desafio para os projetos arquitetônicos, visto que tal ocorrência é muito comum. Estima-se que em 15 anos o Brasil estará entre os seis países mais populosos com idade superior a 60 anos (IBGE, 2008). Há ainda uma previsão de aumento de $25 \%$ até 2025 , o que, consequentemente, deve aumentar o índice de pessoas na terceira idade que se envolverão com quedas (ALVES JUNIOR e PAULA, 2008; BRITO et al., 2008; REIS et al., 2010; SOUZA, 2003). 


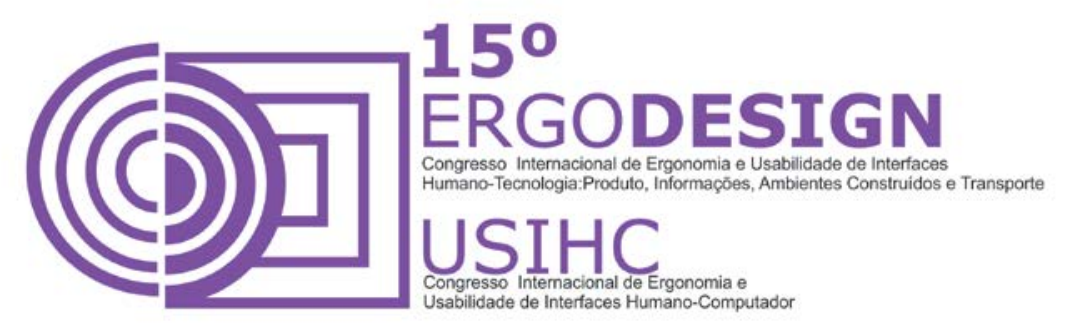

A segurança dos idosos deve ser motivo de preocupação para a sociedade, pois, para essas pessoas, as quedas podem ter repercussões desastrosas, uma vez que idosos com traumas têm perda na sua autonomia e aumento da sua dependência, refletindo em acréscimo de trabalho e estresse para o cuidador e familiares. Segundo a Sociedade Brasileira de Geriatria e Gerontologia (2008), cerca de $28 \%$ a $35 \%$ de idosos com mais de 65 anos e $32 \%$ a $42 \%$ com mais de 75 anos sofreram algum tipo de queda. Para se prevenirem desses acontecimentos, cuidadores e familiares devem se mobilizar em torno de cuidados especiais, adaptando o ambiente em que o idoso vive e tendo o cuidado de observar alguns itens de segurança, como o uso de calçados adequados, tapetes antiderrapantes e disposição da mobília em casa (MACHADO et al., 2009).

Neste sentido, eliminar as barreiras arquitetônicas, principalmente os degraus, pisos irregulares e banheiros não adaptados, deve proporcionar um ambiente seguro e saudável (FREITAG et. al., 2007). Portanto, em qualquer projeto arquitetônico a ergonomia deverá estar presente, visto que o desenho universal deve ser enfocado em todas as edificações, para que assim se possa ter um ambiente acessível a todos com saúde, conforto e principalmente segurança (BINS ELY, 2003).

Também nessa linha de raciocínio é importante considerar, no momento da construção de uma edificação, todos os riscos que possam afetar a saúde humana, principalmente os riscos ergonômicos, químicos e biológicos (FONSECA e RHEINGANTZ, 2009).

Além disso, a estabilidade do corpo depende da recepção adequada de informações através de componentes sensoriais, cognitivos, do sistema nervoso central e musculoesquelético de forma integrada. O efeito cumulativo de alterações relacionadas à idade, doenças e meio-ambiente inadequados parece predispor a quedas (PEREIRA et al., 2001).

Segundo estudo apresentado por Reis et al. (2011) percebe-se que 40\% dos idosos avaliados estão propensos a quedas, tornando-se evidente a necessidade de eliminar os riscos ergonômicos e barreiras arquitetônicas que possam contribuir para o desequilíbrio do idoso. Já Rebelatto e Morelle (2007) alertam que após incidência de quedas, deve-se fazer uma análise ergonômica adequada, principalmente avaliando o local e hora do acidente.

Os fatores associados como o tipo do piso, do calçado, tapetes, piso escorregadio, condição funcional e utilização de medicamentos devem ser relatados na análise, para que a correção seja feita adequadamente. Bins Ely e Cavalcanti (2001) alertam que um projeto arquitetônico mal construído para as pessoas idosas poderá proporcionar sérias consequências para esta população, pois barreiras arquitetônicas oriundas deste projeto contribuirão para acidentes e perda da mobilidade funcional.

\subsection{Fatores Relacionados à Queda}

O Centro Colaborador para a Qualidade do Cuidado e Segurança do Paciente (PROQUALIS, 2012) desenvolveu um protocolo de quedas, no qual são consideradas como quedas quando: o paciente é encontrado no chão; o paciente é amparado durante a queda (mesmo que não chegue ao chão); e o paciente escorrega de uma cadeira/poltrona/vaso sanitário para o chão. 


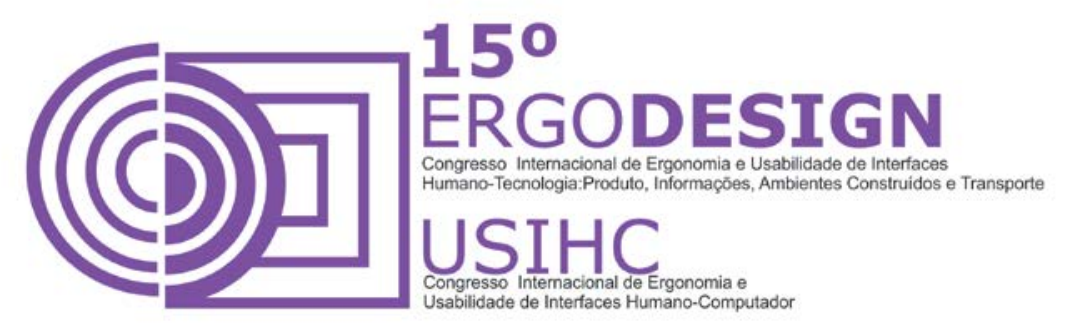

Além disso, os fatores que predispõem ao risco de queda são: alteração do estado mental (confuso ou agitado); distúrbios neurológicos; prejuízo do equilíbrio da marcha; déficit sensitivo; quedas anteriores; uso de medicamentos que alteram o sistema nervoso central; idade acima de 60 anos; todas as crianças; e urgência urinária/intestinal (PROQUALIS, 2012).

Portanto, para a avaliação dos riscos de queda os seguintes critérios devem ser seguidos:

- Todos os pacientes com risco de queda são avaliados pelo enfermeiro, diariamente, a partir da admissão até o momento da alta;

- O impresso para avaliação de risco é preenchido individualmente por paciente.

- É considerada existência de risco de queda se for identificado um ou mais fatores de risco;

- Após avaliação, se detectado risco de queda, o enfermeiro realiza o diagnóstico de enfermagem, implementa as medidas preventivas padronizadas e outras de caráter individualizado;

- A Comissão de Prevenção de Queda elabora o Banco de dados das notificações de queda, bem como analisa as ocorrências, para posterior análise estatística pelo núcleo de epidemiologia e confecção de relatório técnico (PROQUALIS, 2012).

\subsection{Análise de um Estudo de Caso}

Em um estudo de caso realizado por Barela et al. (2012), foram analisadas 50 amostras (quartos), sendo 14 no período da manhã, 18 à tarde e 18 à noite. Neste estudo foi observado que $92 \%$ dos pacientes pertenciam a um grupo de risco que envolve quedas, mas apenas $43 \%$ dos pacientes foram devidamente orientados quanto ao risco. Em relação aos acompanhantes, $80 \%$ destes receberam orientação quanto ao risco, porém sem saber que medidas tomar para a prevenção.

Observou-se os seguintes problemas:

- apenas $29 \%$ das grades das camas encontravam-se elevadas e $39 \%$ das camas encontravam-se devidamente travadas;

- para pacientes que necessitavam de uso de comadres ou papagaios para desprezar suas necessidades, apenas 39\% estavam com tais objetos próximos às suas respectivas camas;

- para os paciente que conseguiam deambular, apenas $56 \%$ dos leitos tinham escadinha de apoio de fácil visualização;

- aos que conseguiam ir ao banheiro, em $100 \%$ dos casos estes apresentavam pisos antiderrapantes, de acordo com a Norma Regulamentadora NR24 (BRASIL, 2008) que determina que os pisos devem ser impermeáveis, laváveis, de acabamento liso, inclinado para os ralos de escoamento providos de sifões hidráulicos, devendo impedir a entrada de umidade e emanações no banheiro, e não apresentando ressaltos e saliências e com campainha (BARELA, et al., 2012). Porém, mesmo sendo 


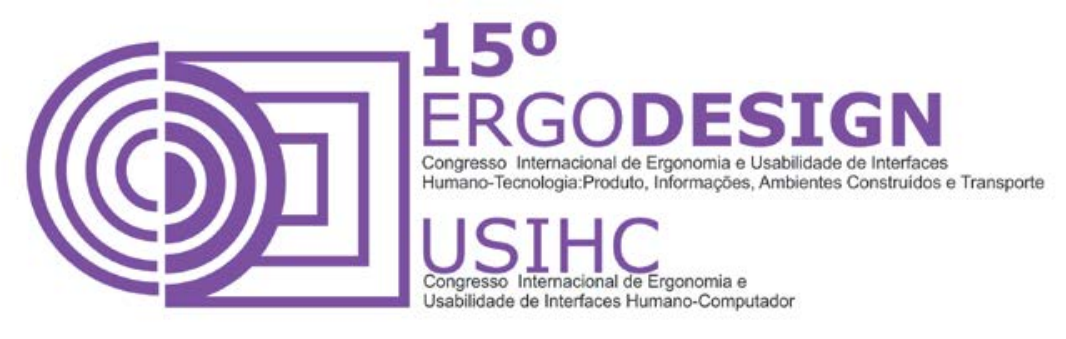

antiderrapantes, 56\% dos banheiros encontravam-se escorregadios por apresentarem água em seu piso;

- em avaliação ambiental do quarto, 59\% não apresentava campainhas próximas ao leito do paciente, $49 \%$ do ambiente apresentava móveis em excesso, $28 \%$ com iluminação inadequada (considerando os três períodos do dia em que a avaliação foi realizada); isolando o período noturno, apenas $50 \%$ apresentava-se devidamente iluminado (BARELA, et al., 2012).

A Sociedade Brasileira de Geriatria e Gerontologia (2008) afirma que os pacientes que já sofreram quedas estão mais propensos a requererem institucionalização, fato esse observado nesse estudo, pois apenas 38\% consideravam o quarto como sendo não familiar, devido a internações prolongadas e reinternações, sendo poucas as novas internações.

\section{MATERIAIS E MÉTODOS}

Para o desenvolvimento deste estudo foram realizadas avaliações em quartos similares de modo a verificar os possíveis fatores contribuintes para a ocorrência de quedas. Na sequência foram definidos requisitos para o desenvolvimento da proposta. O levantamento de quartos baseou-se em estudos preliminares e imagens da internet, dessa forma, foi possível conhecer alguns modelos existentes, podendo avaliar o que havia de projeto de prevenção de quedas, visando assim a segurança do paciente.

\section{RESULTADOS}

\subsection{Características dos Quartos Similares}

Dos quartos e fatores analisados foram destacados:

a) Iluminação e campainha: quanto à iluminação observou-se no quarto 1, demonstrado na Figura 1, que não havia iluminação na cabeceira da cama e nem fonte de luz no chão que pudesse facilitar a visualização do mesmo em momentos de deambulação. Ao mesmo tempo nota-se a inexistência de campainha para solicitação dos profissionais de saúde.

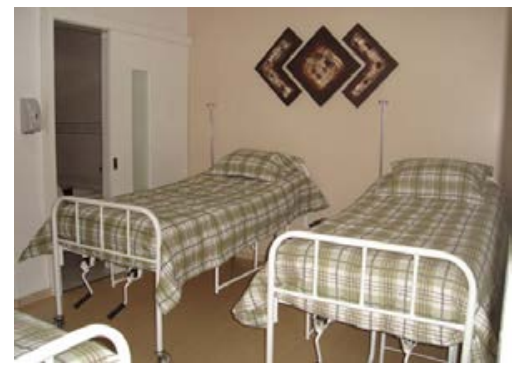

Figura 1 - Falta de lluminação adequada

Fonte: <http://www.casavivabem.com.br/galeria.php> Acesso em 12 ago. 2014 


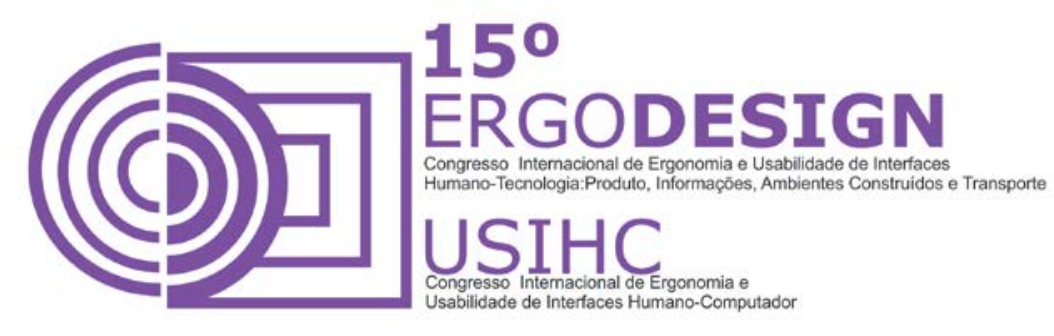

b) Grades de proteção: no quarto 2 (Figura 2) verificou-se que as camas encontravamse muito próximas umas das outras, dificultando a circulação pelo ambiente e a falta de grades de segurança que deveriam existir nas camas para propiciar segurança aos pacientes.

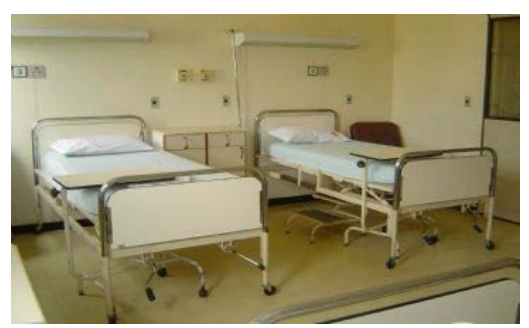

Figura 2 - Falta de grades de proteção

Fonte: <http://www.plenaagp.com.br/?pagina=noticias/noticia.asp\&codigo=428> Acesso em 12 ago. 2014

c) Excesso de mobília: no quarto 3 (Figura 3) foi possível obervar o excesso de mobília, o que dificultava não somente a deambulação dos pacientes, mas também o trabalho dos profissionais de saúde.

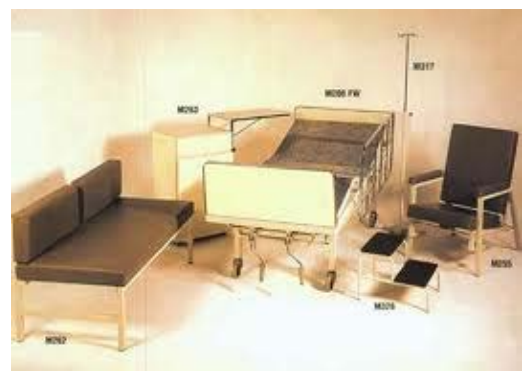

Figura 3 - Excesso de mobília

Fonte: http://t1.gstatic.com/images?q=tbn:ANd9GcSW0jGmpyB1xajelQE1viwcEcu_QKVYn3JTBevm2VzyyM4efdeCQ> Acesso em 12 ago. 2014

\subsection{Requisitos para o Projeto}

Foram elaborados alguns requisitos (Tabela 1) para o desenvolvimento da proposta, os quais serviram como base para a busca de soluções.

\section{Tabela 1 - Lista de requisitos}

\section{REQUISITOS}

Camas travadas

Quarto devidamente iluminado

Visualização adequada dos acessórios do quarto

Escadinha de apoio de fácil visualização

\section{FINALIDADE}

A cama deve ter travas em suas rodas, evitando o deslizamento.

O quarto deve ser devidamente iluminado para melhor visualização do ambiente, mobílias e corredores de acesso.

Para evitar acidentes com mobílias, deve-se ter uma ótima visualização dos acessórios do quarto.

Prevenindo acidentes com as escadinhas, as mesmas devem ser de fácil visualização, inclusive à noite. 


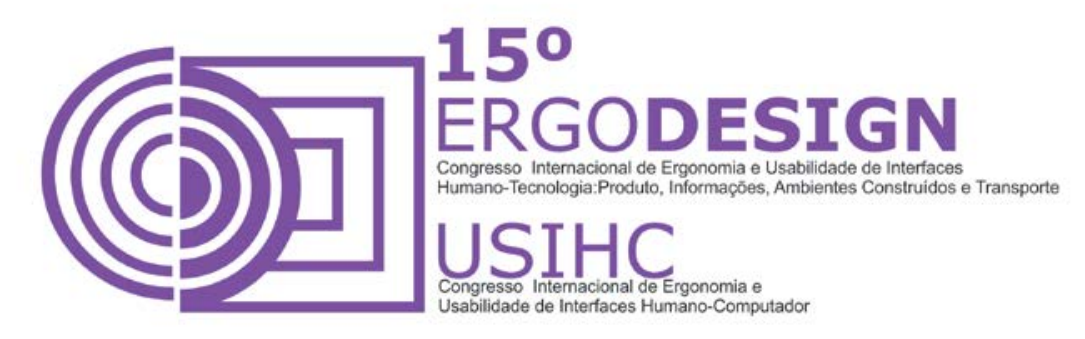

\begin{tabular}{|l|l|}
\hline $\begin{array}{l}\text { Banheiro } \\
\text { devidamente seco (após banho) }\end{array}$ & $\begin{array}{l}\text { Prevenindo acidentes nos banheiros, os mesmos devem estar devidamente } \\
\text { secos, principalmente após o banho. }\end{array}$ \\
\hline $\begin{array}{l}\text { Piso antiderrapante } \\
\text { Papagaio ou comadre perto do } \\
\text { paciente }\end{array}$ & $\begin{array}{l}\text { Em virtude do grande número de pacientes acamados, objetos de uso } \\
\text { necessário como papagaios ou comadres, devem estar perto dos mesmos, } \\
\text { evitando assim que eles se levantem da cama. }\end{array}$ \\
\hline Campainhas próximas ao leito & $\begin{array}{l}\text { Para solicitação de auxílio da equipe de saúde, deve-se ter campainhas } \\
\text { próximas aos leitos dos pacientes. }\end{array}$ \\
\hline Campainhas nos banheiros & $\begin{array}{l}\text { Para solicitação de auxílio da equipe de saúde, após uso do banheiro, deve- } \\
\text { se ter campainhas dentro do mesmo. }\end{array}$ \\
\hline $\begin{array}{l}\text { Óculos e próteses auditivas } \\
\text { próximas ao paciente }\end{array}$ & $\begin{array}{l}\text { Prevenindo acidentes, óculos, próteses auditivas devem ficar próximos aos } \\
\text { pacientes, evitando que o mesmo se levante para pega-los. }\end{array}$ \\
\hline $\begin{array}{l}\text { Ambiente com muitos móveis e } \\
\text { objetos }\end{array}$ & $\begin{array}{l}\text { Para facilitar o deslocamento tanto do paciente quanto da equipe de saúde, } \\
\text { a mobília do quarto deve ser moderada, não podendo estar em excesso ou } \\
\text { fora de seus lugares. }\end{array}$ \\
\hline
\end{tabular}

Fonte: Elaborado pelos autores

\subsection{Aplicação no Projeto}

De acordo com os requisitos estabelecidos, foram definidos diversos parâmetros para a readequação do ambiente, como iluminação, piso, mobília, entre outros. A Figura 4 apresenta 0 layout com a disposição dos elementos básicos do ambiente.

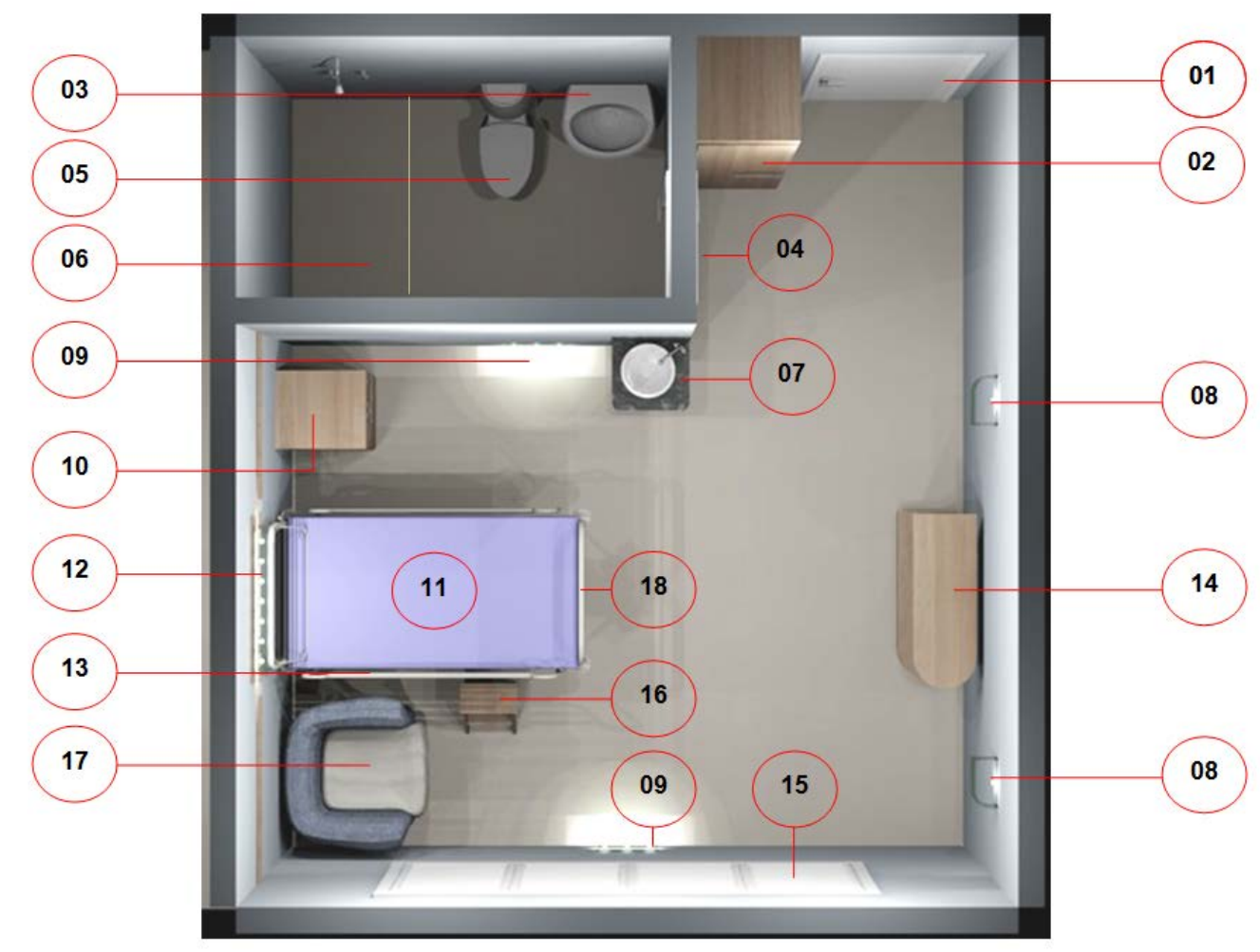




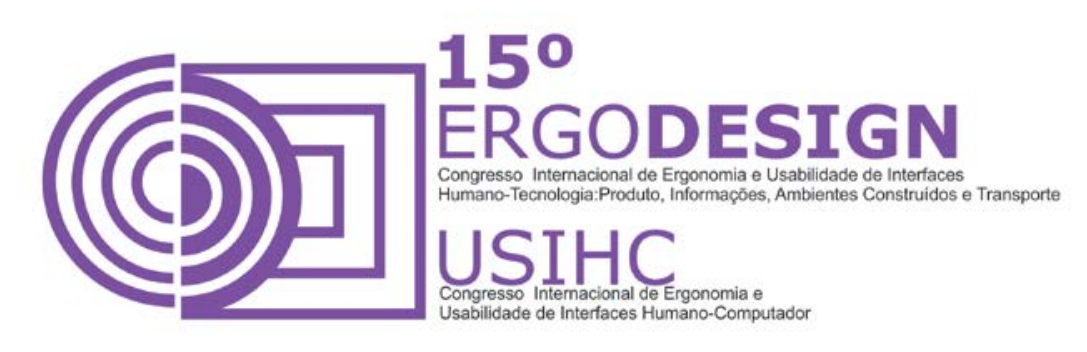

\begin{tabular}{|c|c|c|c|}
\hline \multicolumn{4}{|c|}{ LEGENDA } \\
\hline 01 & Porta de entrada & 10 & Mesa de cabeceira \\
\hline 02 & Armário embutido & 11 & Cama hospitalar \\
\hline 03 & Lavatório do banheiro & 12 & Luminária sobre a cama \\
\hline 04 & Porta do banheiro & 13 & Grade da cama \\
\hline 05 & Vaso sanitário & 14 & Mesa móvel de refeição \\
\hline 06 & Box do chuveiro & 15 & Janela do quarto \\
\hline 07 & Lavatório do quarto & 16 & Escadinha \\
\hline 08 & Luminária de parede & 17 & Poltrona \\
\hline 09 & Luminária de rodapé & 18 & Base da cama \\
\hline
\end{tabular}

\section{Figura 4 - Layout do quarto readequado}

Fonte: Elaborado pelos autores

\section{$5.1 \quad$ Cama}

Visando maior proteção ao paciente, a colocação de grade de proteção que contemple toda a extensão da cama garante maior segurança ao paciente e evita que aqueles que apresentarem alguns distúrbios saiam da cama por espaços presentes entre grade e cama. O uso de travas nas rodas da cama evita o deslizamento da mesma nos momentos em que o paciente a acessa (Figura 5).

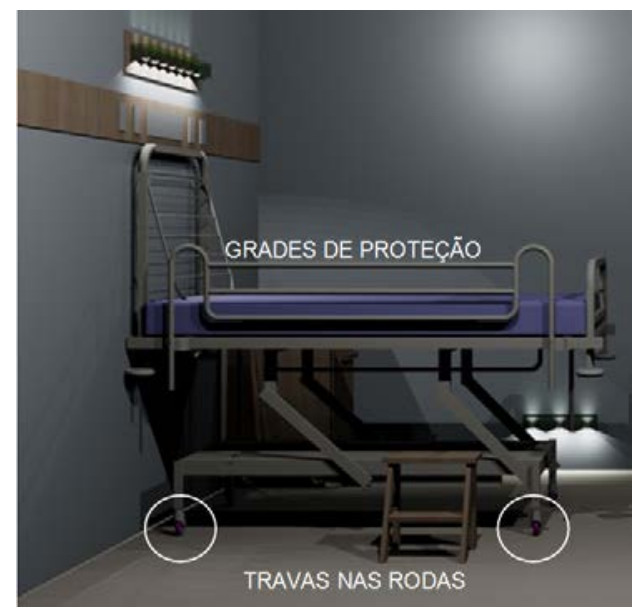

Figura 5 - Grades da cama

Fonte: Elaborado pelos autores

\subsection{Iluminação de teto, parede, cabeceira e rodapé}

A iluminação no teto e parede propicia a visualização do ambiente como um todo, a luz na cabeceira facilita a execução de procedimentos realizados pelos profissionais e, a iluminação no rodapé permite melhor visualização do chão e mobílias, facilitando a deambulação (Figura $6)$. 

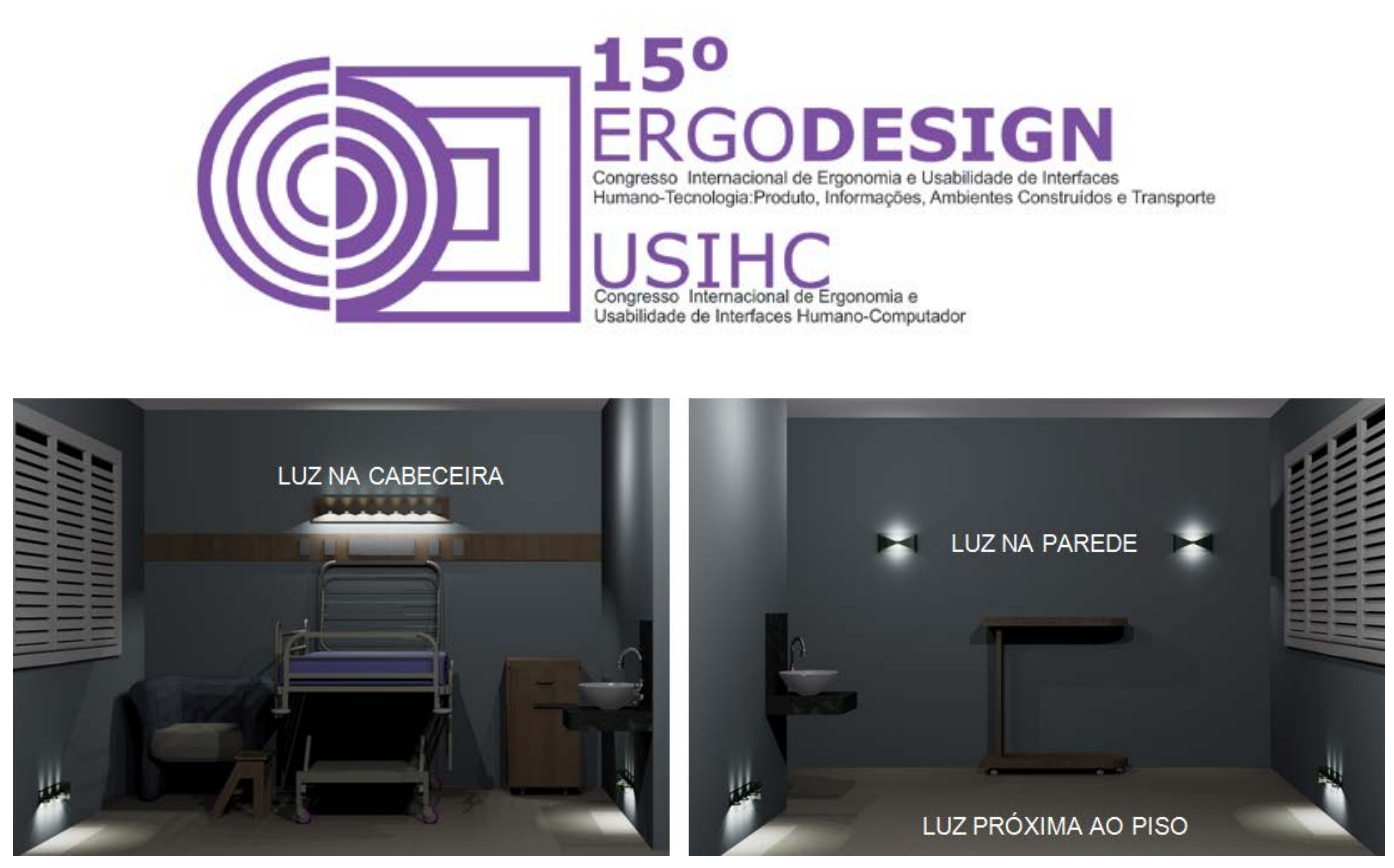

Figura 6 - lluminação

Fonte: Elaborado pelos autores

\subsection{Pisos}

Os pisos devem ser antiderrapantes, principalmente no banheiro, fator primordial fundamental na prevenção de queda após o banho. Além da escolha do piso, mantê-lo sempre seco e limpo proporciona higiene e segurança ao paciente.

\subsection{Campainhas}

A campainha deve ser posicionada próxima ao leito do paciente para solicitação da equipe de saúde prestadora de serviço, evitando que o mesmo tente levantar-se da cama para pedir auxílio. Em alguns casos a ajuda dos prestadores de serviço é necessária também no banheiro, e o uso de campainha dentro do banheiro faz-se necessário para maior segurança.

\subsection{Escada de apoio}

A escada de apoio e acesso deve estar bem posicionada e visível para o acesso à cama. A colocação de faixas refletivas nos degraus facilita sua visualização no período noturno (Figura 7). 

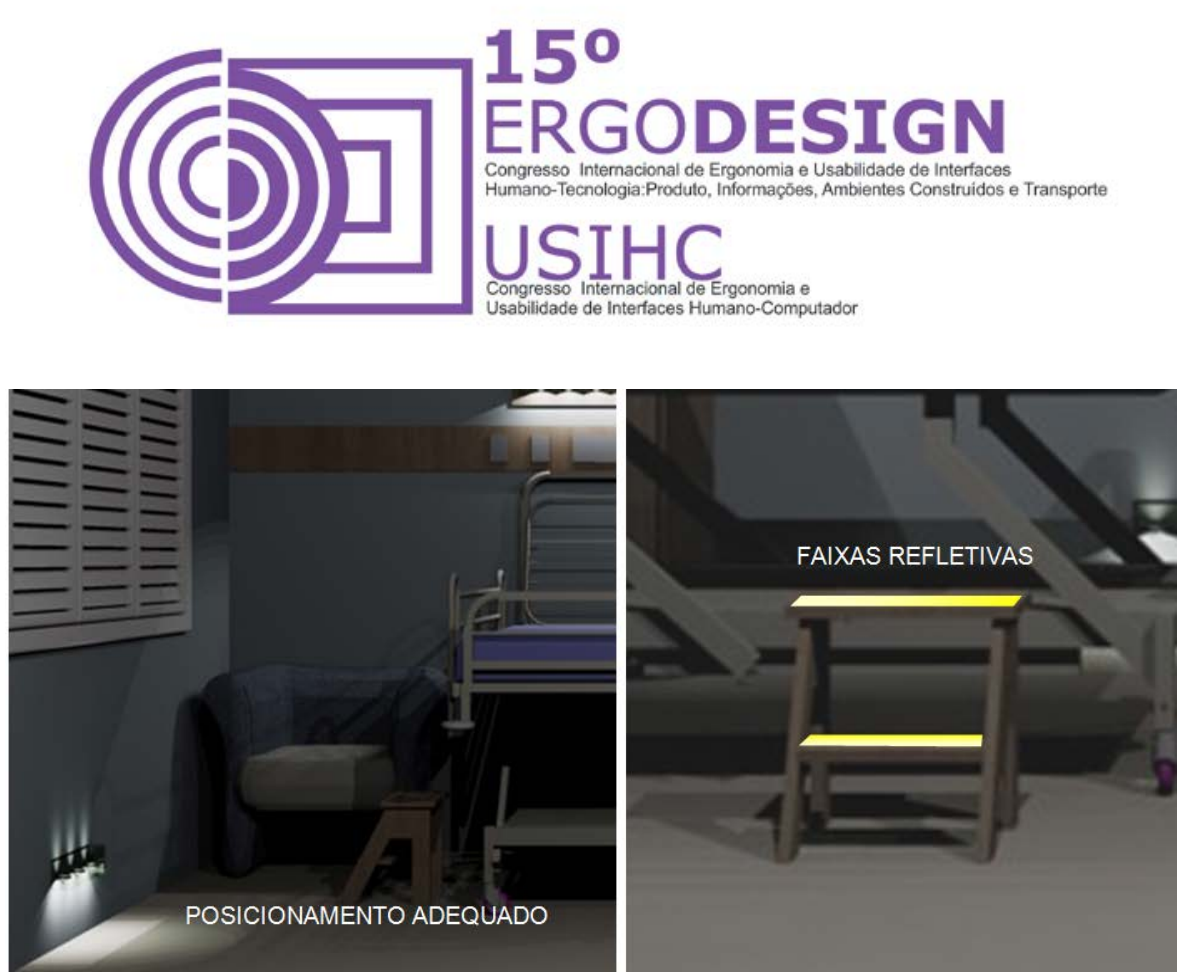

Figura 7 - Escada de apoio

Fonte: Elaborado pelos autores

\subsection{Orientação aos acompanhantes e visitantes}

A orientação verbal aos acompanhantes é de grande importância, principalmente visando que a segurança do paciente seja preservada, evitando, por exemplo, que os acompanhantes saiam do quarto e deixem a cama destravada ou grades rebaixadas. No ato da visita orientação escrita deve ser distribuída aos visitantes contendo as instruções sobre visitas, mas também sobre as normas de segurança do paciente.

Em síntese, o projeto realizado trata-se de uma adaptação do ambiente hospitalar adequando-o ao protocolo do risco de queda. Sendo assim, primeiramente o edifício hospitalar deve garantir um ambiente saudável, aconchegante, como forma de auxiliar na cura, e acompanhar o rápido avanço da medicina e da tecnologia. É no processo de projeto que se pode garantir que todas as necessidades do edifício hospitalar sejam atendidas, fazendo com que tanto o projeto quanto a produção sejam elaborados com qualidade de forma a garantir o atendimento, aumentando a construtibilidade e diminuindo os custos do empreendimento.

\section{CONSIDERAÇÕES FINAIS}

Conforme avaliado no presente estudo, constatou-se ainda uma grande necessidade de orientação, não somente quanto ao risco de quedas por parte dos pacientes e dos acompanhantes, como também os meios para se evitar tais eventos adversos.

O presente estudo afirma ainda que a distribuição espacial das unidades funcionais e de seus respectivos ambientes deve ser estudada levando-se em consideração os fluxos, que podem ser divididos em dois conjuntos: interfuncionais (que se desenvolvem entre diferentes unidades funcionais) e intrafuncionais (que se desenvolvem dentro de uma única unidade funcional), sendo assim os projetos estruturais devem visar segurança e conforto dos usuários, concomitante à afirmação anterior da Sociedade Brasileira de Geriatria e Gerontologia (2008), que enfatiza a importância de uma anamnese aos usuários avaliando se houve quedas 


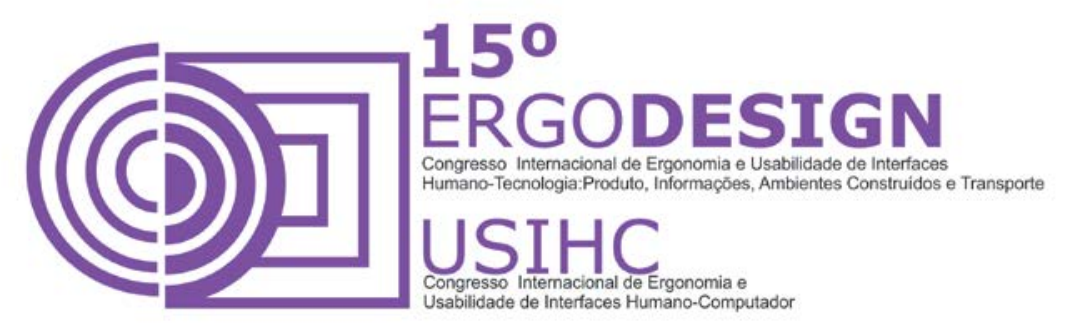

anteriores e suas circunstâncias, bem como o uso ou alterações de medicamentos, doenças músculos-esqueléticas, a capacidade funcional e fatores ambientais.

Em virtude disso, deve-se adotar medidas e ações de prevenção como: adequação estrutural do ambiente hospitalar visando a segurança e conforto do usuário; manter a campainha ao alcance do paciente e orientá-lo a utilizá-la para solicitação da presença do profissional de enfermagem; manter ao alcance do paciente os pertences e objetos mais utilizados (coletor de urina, óculos, entre outros); manter a cama com as rodas travadas; manter as grades de proteção elevadas; manter a área de circulação das enfermarias e corredores livre de móveis e utensílios; não deixar o ambiente totalmente escuro, tendo além de luminária central, luminária de cabeceira e de rodapé; orientar o uso de calçados antiderrapantes, com pisos antiderrapantes principalmente nos banheiros; entregar, na admissão do paciente, um folder com orientação de prevenção de queda e realizar orientação ao paciente e acompanhante; orientar a família sobre a necessidade de comunicar a enfermagem o período que o paciente possa permanecer sem acompanhante.

Uma forma de se reduzir custos com a assistência ao idoso é prevenindo os eventos de quedas que os mesmos podem sofrer, e para isso deve-se identificar os fatores que contribuem para tais fatos.

A Sociedade Brasileira de Geriatria e Gerontologia (2008) ressalta que a importância dos fatores de risco ainda são poucos estudados de forma consistente e que intervenções realizadas por profissionais especializados podem prevenir acidentes que envolvem quedas.

Da maneira como se apresenta, muitos aspectos humanos devem ser observados e tratados, mas os aspectos ambientais e dos artefatos que compreendem o ambiente hospitalar merecem maior atenção, especialmente no que refere ao desenvolvimento de estudos que complementem de informação as devidas interferências projetuais nestes ambientes. Neste sentido, o design ergonômico deve garantir condições que contribuam para a segurança do usuário, propondo parâmetros projetuais efetivos à qualidade de todo sistema.

\section{REFERÊNCIAS BIBLIOGRÁFICAS}

ALVES JUNIOR, E. D.; PAULA, F. P. A prevenção de quedas sob o aspecto da promoção da saúde. Fitness \& Performance Journal, Rio de Janeiro, v.7, n.2, p.123-129, 2008.

BARELA, J.; COSTA, W. B.; FERREIRA, A. C. M.; Protocolo de Quedas: Avaliação de Ambientes Hospitalares na Prevenção dos Riscos. In: SIMPÓSIO INTERNACIONAL DE INICIAÇÃO CIENTÍFICA, 20., 2012. Rlbeirão Preto. Disponível em: <https://uspdigital.usp.br/siicusp/cdOnlineTrabalhoVisualizarResumo?numerolnscricaoTrabalho=910\&nu meroEdicao=20> Acesso em 20 jan. 2015.

BINS ELY, V. H. M.; CAVALCANTI, P. B. Avaliação dos Asilos para Idosos em Florianópolis. Relatório de pesquisa PETARQ - UFSC. Florianópolis, 2001.

BINS ELY, V. H. M. Ergonomia + Arquitetura: buscando um melhor desempenho do ambiente físico. Anais do $3^{\circ}$ Ergodesign. Rio de Janeiro: LEUI/PUC-Rio, 2003. 


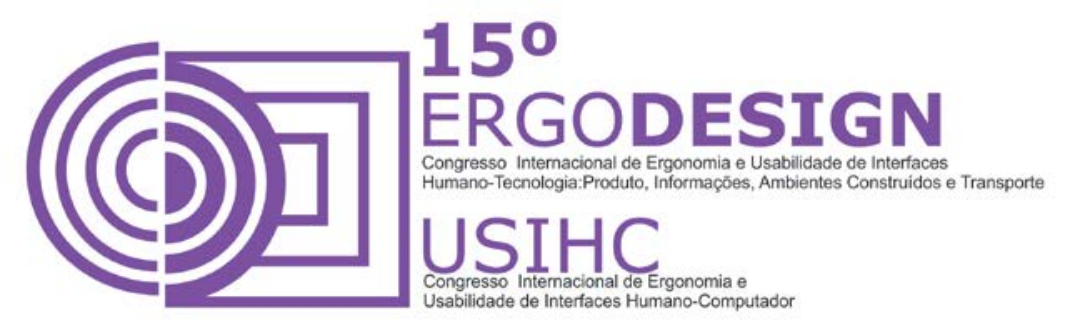

BRASIL - Norma Regulamentadora NR24 - Normas de Segurança e Saúde no Trabalho, D.F. 2008. Disponível em: <http://www.normaslegais.com.br/legislacao/port-sit-320-2012-Consulta-PublicaNR24.pdf> Acesso em 20 jan. 2015.

BRITTO, R. R. SANTIAGO, L. ELIZA, R. Comportamento e Barreiras: Atividade Física em Idosos Institucionalizados. Psicologia: Teoria e Pesquisa, v. 24 n. 4, p. 451-458, out/dez 2008.

FONSECA, J. F.; RHEINGANTZ, P. A. O ambiente está adequado? Prosseguindo com a discussão. Rev. Produção, v.19, n.3, p. 502-513, 2009.

FREITAG, L. M. P.; ARAGÃO, A. E.; ALMEIDA, P. C. Acessibilidade e deficiência física: identificação de barreiras arquitetônicas em áreas internas de hospitais de Sobral, Ceará. Rev Enferm USP. v. 41 n.4 p. 581-588, São Paulo, 2007.

INSTITUTO BRASILEIRO DE GEOGRAFIA E ESTATÍSTICA (IBGE). Indicadores populacionais. Rio de Janeiro, 2008.2 Disponível em: <http://www.ibge.gov.br/home/estatistica/populacao/projecao_da_populacao/2008/projecao.pdf> Acesso em 20 jan. 2015.

MACHADO T. R; et al - Avaliação da presença de risco para queda em idosos. Rev. Eletrônica de Enfermagem, v. $11, \quad$ n. 1 , p. 32-8, 2009. Disponível em: <http://www.fen.ufg.br/revista/v11/n1/v11n1a04.htm> Acesso em 20 jan. 2015.

PEREIRA, S. R. M.; BUKSMAN, S.; PERRACINI, M.; PY, L.; BARRETO, K. M. L.; LEITE, V. M. M. Quedas em idosos. Rio de Janeiro: Sociedade Brasileira de Geriatria e Gerontologia, 2001.

SOCIEDADE BRASILEIRA DE GERIATRIA E GERONTOLOGIA. Quedas em Idosos: Prevenção. In: Projeto Diretrizes, Rio de Janeiro, 2008.

PROQUALIS - Aprimorando as praticas de saúde. Anexo 01: Protocolo prevenção de quedas, 2012. Disponível em: <http://proqualis.net/sites/proqualis.net/files/Protocolo\%20\%20Preven\%C3\%A7\%C3\%A30\%20de\%20Quedas.pdf > Acesso em 20 jan. 2015.

REBELLATO, J.R.; MORELLE, J.G.S. Fisioterapia Geriátrica - A prática da assistência ao idoso. São Paulo: Manole, 2007.

REIS, P. F; MORO, A. R. P., MERINO, E. D. Influência dos Riscos Ergonômicos na Acessibilidade do Idoso Cadeirante Residente em Instituição de Longa Permanência. In: XVI CONGRESSO BRASILEIRO DE ERGONOMIA e III Congresso Latino Americano de Ergonomia da ULAERGO, 2010, ABERGO, 2010.

RIBEIRO, A. P.; SOUZA, E. R. de; ATIE, S.; SOUZA, A. C. de; SCHILITHZ, A. O. A influência das quedas na qualidade de vida de idosos, Ciências \& Saúde Coletiva, v. 13, n. 4, p.1265-1273, 2008.

SOUZA, A.C.A. Quedas no idoso. In: TERRA, N.L. Entendendo as queixas do idoso. Porto Alegre: EdiPURCS, 2003. 